Www.jmscr.igmpublication.org

Impact Factor (SJIF): 6.379

Index Copernicus Value: 79.54

ISSN (e)-2347-176x ISSN (p) 2455-0450

crossrefDOI: https://dx.doi.org/10.18535/jmscr/v7i1.35

Journal Of Medical Science And Clinical Research

IGM Publication

An Official Publication of IGM Publication

\title{
A Qualitative Study of Birth Preparedness and Complication Readiness among Community Members in a Rural Area
}

\author{
Author \\ Dr Ashima Bhaumik* \\ Assistant Professor, Department of Community Medicine, KJ Somaiya Medical College and Research \\ Centre, Mumbai, India \\ *Corresponding Author \\ Dr Ashima Bhaumik
}

Email: ashimabhaumik2004@yahoo.com

\begin{abstract}
Birth preparedness and complication readiness $(B P / C R)$ comprise a strategy to make women plan for birth, recognize common complications and encourage them to seek professional care in order to reduce poor pregnancy outcome by reducing the delays in seeking, reaching or receiving care. However, there are lacunae somewhere as the BP/CR messages do not translate to complete comprehension and full utilization of facility delivery. This qualitative study using focus group discussions (FGDs) explores the perceptions of the community on BP/CR.

Methods: Six FGDs were conducted during May-June 2016. The FGDs had 10-12 participants in each group. Each group comprised older men and women and young men and women in a community in rural Maharashtra. A pretested questionnaire was used to conduct the FGDs. The topics for discussion centred around community experiences with antenatal and postnatal care services, cultural and social issues surrounding birth preparedness, recognition of maternal danger signs, and the use of traditional practices during pregnancy and childbirth.

Qualitative content analysis was used to analyse the data.

Results: The study revealed that hospital delivery was perceived to be safer than home delivery. Reasons cited for not attending the minimum requirement of four antenatal care services or two postnatal care services within the first month after delivery included distance to the health facility, poor road conditions and lack of money for transport. Findings included lack of community awareness about the danger signs during pregnancy and childbirth, that traditional birth attendants were important but that deliveries needed skilled care.

Conclusion: This study shows that the perceptions of the community regarding BP/CR are in favour of skilled care. The community is aware of the importance of attending ANC, saving money for buying supplies and organizing transport, but there was little awareness about recognising complications and importance of obstetric emergency care. It is important to provide information on BP/CR and schemes like JSK, JSSK through community health workers particularly during antenatal visits.
\end{abstract}

Keywords: Focus group discussions, perceptions, birth preparedness and complication readiness, rural Maharashtra.

\section{Introduction}

Every pregnancy is a joyful moment for all mothers who visualize being handed a flawless "bundle of joy".
However unpredictable complications can result in disastrous consequences. Worldwide, approximately 830 women died every single day due to complications during pregnancy or childbirth in 2015. ${ }^{(1)}$ Thaddeus and Maine have 
documented 'three delays' in seeking, reaching and obtaining appropriate care as the crucial factors for maternal mortality. ${ }^{(2)}$

Immediate and efficient professional care during antenatal, intra natal and post partum period can make the difference between life and death for a woman and her new born. ${ }^{(3)}$

The Maternal and Neonatal Health Program of JHPIEGO has developed the strategy of Birth preparedness and Complication readiness (BP/CR) addressing the factors that can be averted with advance preparation and rapid action, thus reducing the delays in seeking, reaching or receiving care. ${ }^{(3,4)}$ Knowledge of danger signs, identifying a mode of transport, saving money, identifying a skilled attendant, identifying where to go in case of complications, and identifying a blood donor are all elements of $\mathrm{BP} / \mathrm{CR}^{(5)}$

Reducing the global maternal mortality ratio (MMR) to less than 70 per 100000 live births by 2030 (SDG Target 3.1) will require a global annual rate of reduction of at least $7.5 \%{ }^{(1)}$. It is therefore crucially important to increase women's access to quality care before, during and after childbirth.

In developing countries women have poor knowledge of danger signs as shown in several studies. ${ }^{(6-9)}$ In sub-Saharan countries studies have also found low knowledge of birth preparedness and the practice of BP/CR. ${ }^{(10,11)}$ In a qualitative study on BP/CR in Tanzania by Furaha August (2015) it has been demonstrated that few women attending ANC are counselled on obstetric danger signs during their very short visits. ${ }^{(12)}$ However in a study by Musa et al in Ehiopia more than half of the respondents were prepared for birth and its complications. $^{\text {(13) }}$

There is evidence from India ${ }^{(14)}$ Ethiopia $^{(15)}$ and Ghana $^{(16)}$ that promoting BP/CR improves knowledge about danger signs of pregnancy and childbirth and also preventive and care seeking behaviour.

Maharashtra has many remote rural areas and tribal pockets where the concept of BP/CR is not well understood. This study has been conducted in a group of 5 villages and remote tribal areas. The primary health centre is located 10 kilometres away, government hospitals and MGM hospital at Kamothe are all located 30 kilometres away. Access to the nearby sub centre is hampered by rocky and bad roads. The sub centre does not provide $24 \mathrm{X} 7$ services and the quality of services are often not satisfactory. To sustain the MDG target and go on to achieve the SDG target it is necessary for the concept of BPCR to percolate to all the remote areas. However no study has been done in rural Maharashtra to explore this concept among men and women. The aim of this study was to explore the perceptions, experiences and challenges faced by the community regarding $\mathrm{BP} / \mathrm{CR}$.

\section{Materials and Methods \\ Study design}

A qualitative study design using focus group discussions (FGDs) was employed to explore the perception of the community on BP/CR. FGDs involved group interactions and were used to capturea wealth of information about these perceptions.

\section{Study area}

The study was conducted in 5 villages in catchment area of Tara group Gram Panchayat. The total population is around 6000 . The villages are a part of field practice area of Rural Health Training Centre (RHTC) of the Department of Community Medicine of MGM Medical College, Kamothe.

The FGDs were conducted in the Anganwadi centres of the 5villages.

\section{Study Period}

Six FGDs were conducted during May-June 2016.

\section{Ethical Considerations}

The study protocol was reviewed and cleared by The Institutional Ethical Committee of the institution. The participants were told the aim of the study and that their participation was voluntary, that their identities would not be revealed and that the information they provided 
would only be used for research purposes and would be kept confidential. Verbal consent to participate was given by each of the participants.

\section{Data collection}

Six FGDs were conducted during May-June 2016. The FGDs had 10-12 participants in each group. Each group comprised of older men and women and young men and women (Table 1). A pretested questionnaire was used to conduct the FGDs. The topics for discussion included knowledge about the components of birth preparedness during pregnancy and childbirth, cultural and social issues surrounding it, steps taken to prepare for pregnancy and potential complications during childbirth in the community, recognition of maternal danger signs, and the use of traditional practices during pregnancy and childbirth. (Table 2)

The focus group discussions would begin with the moderator asking the participants to talk and interact about what happens when a woman in their family is pregnant. What are the aspects they look into while preparing for childbirth and how do they propose to tackle emergency situations that may arise during pregnancy, during labour and after childbirth?

The FGDs were conducted in Marathi and were audio-recorded and lasted about 45 minutes to 1 hour. All FGDs were led by a moderator and some notes were taken by an observer.

Table 1 FGD with participants' particulars

\begin{tabular}{|l|c|c|c|c|}
\hline Participants & $\begin{array}{c}\text { Age } \\
\text { range }\end{array}$ & $\begin{array}{c}\text { Avera } \\
\text { ge age }\end{array}$ & $\begin{array}{c}\text { Number of } \\
\text { participants }\end{array}$ & $\begin{array}{c}\text { Number } \\
\text { of FGDs }\end{array}$ \\
\hline Young men & $20-36$ & 25 & 13 & 3 \\
\hline $\begin{array}{l}\text { Young } \\
\text { women }\end{array}$ & $19-34$ & 23 & 16 & 3 \\
\hline Older men & $51-76$ & 55 & 12 & 3 \\
\hline $\begin{array}{l}\text { Older } \\
\text { women }\end{array}$ & $50-74$ & 52 & 14 & 3 \\
\hline
\end{tabular}

Table: 2 Main topics included in the questionnaire used for focus group discussions

\begin{tabular}{|c|c|}
\hline $\begin{array}{c}\text { During pregnancy and } \\
\text { Delivery }\end{array}$ & During postnatal period \\
\hline $\begin{array}{c}\text { Type of ANC services } \\
\text { received }\end{array}$ & $\begin{array}{c}\text { Type of PNC services } \\
\text { received }\end{array}$ \\
\hline $\begin{array}{c}\text { Reasons for attending ANC } \\
\text { services }\end{array}$ & $\begin{array}{c}\text { Reasons for attending PNC } \\
\text { services }\end{array}$ \\
\hline Frequency of ANC visits & Frequency of PNC visits \\
\hline $\begin{array}{c}\text { Constraints of accessing } \\
\text { ANC services }\end{array}$ & $\begin{array}{c}\text { Constraints of accessing } \\
\text { PNC services }\end{array}$ \\
\hline $\begin{array}{l}\text { Satisfaction for using ANC } \\
\text { services }\end{array}$ & $\begin{array}{l}\text { Satisfaction for using PNC } \\
\text { services }\end{array}$ \\
\hline $\begin{array}{l}\text { Knowledge about danger } \\
\text { signs during } \\
\text { pregnancy and childbirth }\end{array}$ & $\begin{array}{c}\text { Knowledge about danger } \\
\text { signs during } \\
\text { Post natal period } \\
\end{array}$ \\
\hline Fee for ANC services & Fee for PNC services \\
\hline $\begin{array}{l}\text { Reasons for not attending } \\
\text { ANC services }\end{array}$ & $\begin{array}{l}\text { Reasons for not attending } \\
\text { PNC services }\end{array}$ \\
\hline $\begin{array}{c}\begin{array}{c}\text { Reasons for using TBA } \\
\text { services }\end{array} \\
\end{array}$ & $\begin{array}{c}\text { Reasons for using TBA } \\
\text { services }\end{array}$ \\
\hline $\begin{array}{c}\text { Community attitude towards } \\
\text { health } \\
\text { Professionals } \\
\end{array}$ & $\begin{array}{c}\text { Community attitude towards } \\
\text { health } \\
\text { Professionals } \\
\end{array}$ \\
\hline $\begin{array}{c}\text { Family support and decision } \\
\text { making on } \\
\text { health services during } \\
\text { pregnancy and labour }\end{array}$ & $\begin{array}{c}\text { Family support and decision } \\
\text { making on } \\
\text { health services during post } \\
\text { natal period }\end{array}$ \\
\hline $\begin{array}{c}\text { Traditional practices and } \\
\text { beliefs during } \\
\text { Pregnancy and labour }\end{array}$ & $\begin{array}{c}\text { Traditional practices and } \\
\text { beliefs during } \\
\text { post natal period }\end{array}$ \\
\hline $\begin{array}{c}\text { Government schemes } \\
\text { discussed/not } \\
\text { discussed during ANC visits }\end{array}$ & \\
\hline
\end{tabular}

\section{Data analysis}

A qualitative content analysis approach, as described by Graneheim and Lundman, was used to analyse the data. ${ }^{(17)}$ The manifest meanings expressed were looked for during the analysis. The recorded and written textual material was read several times to understand the crux of the expressed views. ${ }^{(12)}$ The thematic unitswere configured according to relevance criteria or aim of the study. Categories and subcategories were developed. Table 3.

\section{Results}

During the analysis, 'Birth preparedness important for all births', 'If complications arise then hospital care necessary', and 'Midwives and birth attendants necessary' were the manifest meanings and each of these were divided into 
several subcategories. Views of some participants which emerged from the FGDs are quoted.

Table 3 Categories and subcategories on perception of birth preparedness and complication readiness

\section{Birth preparedness is important for all births}

- ANC important but has challenges

- Facility delivery preferred

- Reason for irregular ANC check up due to economic reasons/distance/poor roads.

2. If complications arise then hospital care necessary'

- Recognising danger signs

- Health centre services known to be free but practically often not so

- Men decide but in consultation

- Traditional beliefs are given less importance than before

- Government schemes are not discussed during ANC visits

3 Midwives and traditional birth attendants necessary

- Necessary in the case of home deliveries.

- They live within the community and hence they are readily accessible.

\section{Birth preparedness is important for all births}

\section{ANC important but has challenges}

It was discussed that it is essential to make ANC visits and preparations for delivery at the hospital, though in the past women would attend for the first time at term or if they had pregnancy or childbirth related problems. The practice now however is to attend for check-ups at the health centre/hospital and most women deliver in hospital.

\section{Reasons cited for not attending ANC/PNC visits}

These reasons include distance to the health facility and lack of money for transport, bad roads, or if there was no one to tend to their children in their absence.

"We live far from the health centre and the roads are bad. I may have to deliver right here though I do not want to." (Young woman, FGD)

"I am not sick why should I go to the midwife/health centre [after delivery]? I do not want to waste my money. My mother-in-law is old and cannot tend to my son"(A young mother, FGD)

\section{Facility delivery is preferred}

Hospital delivery was perceived to be safer than home delivery. Confidence in the competency of the well-trained health workers was also expressed. They also stated that, in this community, few women deliver at home (except in the adivasipada of Banbaiwadi).

"I will feel safe if I deliver in hospital. During delivery my sister had a lot of trouble but she delivered safely in hospital."(A 23 year old pregnant woman during FGD)

Although facility delivery is preferred, at times the intention to do so was not always followed. Traditional birth attendants (TBAs) are consulted in the case of home deliveries. They live within the community and hence they are readily accessible and can come quickly to the home. TBAs are preferred for attendance at home during pregnancy and advising instead of regular visits to health centre. This is cheaper.

"I called the village midwife because my son's wife had some bleeding in the 4th month of pregnancy. It was cheaper to call her than to arrange for vehicle." (Older woman, FGD)

\section{If complications arise then hospital care necessary}

\section{Recognising danger signs}

The FGD participants mentioned few complications that may occur during pregnancy and childbirth like fits during pregnancy, prolonged labour, excessive vaginal bleeding after childbirth.

However many common complications were unknown to most women and they felt that such issues were not discussed during ANC visits. They stated that they could go to the health centre and the doctor would advise.

\section{Health centre services known to be free but practically often not so}

Despite the fact that the community prefers to go to a health facility and know that the services are free, they reported that they are told to buy drugs and other essentials. 
"Health workers often tell the pregnant woman to bring a new blade, clean clothes, gloves and thread for the delivery. If they do not they are scolded. This happened to my friend's son?" (Older man, FGD)

\section{The husband/men take the decision but in consultation}

Participants reported that the decision to go to health facility for delivery or emergency is usually made by the husband but in consultation with other older members of the family.

\section{Traditional beliefs are given less importance than before}

The community explained that in the past they used to believe that eating certain foods like eggs, green leafy vegetables was detrimental to the unborn foetus but now they believe the opposite. TBAs sometimes advised to apply cow dung on the umbilical cord after delivery but most women said that this was an old custom only.

\section{Government schemes are not discussed during ANC visits}

The community was not aware about schemes like JSY, JSSK which provide help in emergency situations.Studies by Mukhopadhyay et al in West Bengalreveal poor aawareness about assistance provided by these government schemes. (14) According to Concurrent evaluation of NRHM (2009), 48.7\% women had awareness about JSY in India. ${ }^{(18)}$

\section{Strengths and limitations}

This qualitative study using different participants in terms of age, and gender was strength because this provided different perspectives of how BP/CR is discussed and used.

A possible limitation is that the participants may not have disclosed their true perceptions and have given socially correct answers as the interviews were conducted by doctors and medical staff.

Another limitation is that women are introvert by nature. However, the women participants in my study were eager to participate and interact with one another.

\section{Conclusions}

This study shows that the perceptions of the community regarding $\mathrm{BP} / \mathrm{CR}$ are in favour of skilled care. The community is aware of the importance of attending ANC, saving money for buying supplies, but there was little awareness about recognising complications and importance of obstetric emergency care. This awareness could be improved by providing information on birth preparedness messages through community health workers during the routine antenatal visits.

Issues related to distance, poverty, informal costs, inability to prepare in advance hinder the realisation of the intention to use skilled care.

The community does not have a mechanism in place to help those who are in need in case of an emergency.

It is important to innovate on how the community reinforces BP/CR, such as using the schemes like JSK, JSSK.

\section{Acknowledgements}

I owe my sincerest thanks to members of the community who have enthusiastically participated in my study. It is their wholehearted co-operation that has made my study possible.

\section{References}

1. Alkema L, Chou D, Hogan D, Zhang S, Moller A-B, Gemmill et al. Global, regional, and national levels and trends in maternal mortality between 1990 and 2015, with scenario-based projections to 2030: a systematic analysis by the UN Maternal Mortality Estimation InterAgency Group. Lancet. 2016;387(10017):462- 74 (http://www.thelancet.com/pb/assets/raw/L ancet/pdfs/ S0140673615008387.pdf, accessed 24 December 2018). 
2. Thaddeus S, Maine D. Too far to walk: maternal mortality in context. SocSci Med 1994; 38(8):1091-1110.

3. JHPIEGO. Maternal and neonatal health. Monitoring birth preparedness and complication readiness, tools and indicators for maternal and newborn health. Johns Hopkins, Bloomberg school of Public Health, Center for communication programs, Family Care International; 2004. Available at: http://pdf.dec.org/pdf_docs/

PNADA619.pdf.3) Thaddeus S, Maine D. Too far to walk: maternal mortality in context. SocSci Med 1994; 38(8):10911110 .

4. Maternal and neonatal health (MNH) progam. Birth preparedness and complication readiness:A matrix of shared responsibility. $\quad$ s.l. : $\quad \mathrm{MNH}$, 2001.http://pdf.usaid.gov/pdf_docs/PBAA C802.pdf

5. Moran AC,et al, Birth-preparedness for maternal health: findings from Koupéla District, Burkina Faso. J health PopulNutr 2006 Dec;24(4):489-97.

6. Pembe A, Urassa D, Carlstedt A, Lindmark G, Nystrom L, Darj E. Rural Tanzanian women's awareness of danger signs of obstetric complications. BMC Pregnancy Childbirth. 2009;9:12. [PMC free article] [PubMed]

7. Mutiso S, Qureshi Z, Kinuthia J. Birth preparedness among antenatal clients. East Afr Med J. 2008;85:275-83.[PubMed]

8. Kabakyenga J, Ostergren P-O, Turyakira E, Pettersson K. Knowledge of obstetric danger signs and birth preparedness practices among women in rural Uganda. Reprod Health. 2011;8:33. [PMC free article] [PubMed]

9. Hailu D, Berhe H. Knowledge about obstetric danger signs and associated factors among mothers in Tsegedie District, Tigray Region, Ethiopia 2013: community based

cross-sectional study. PLoS One. 2014;9:e83459.

10. Hiluf M, Fantahun M. Birth preparedness and complication readiness among women in Adigrat town, north Ethiopia. Ethiop $\mathrm{J}$ Health Dev. 2007;22:14-20.

11. Markos D, Bogale D. Birth preparedness and complication readiness among women of child bearing age group in Gobaworeda, Oromia region, Ethiopia. BMC Pregnancy Childbirth. 2014;14:282. [PMC free article][PubMed]

12. Furaha August, Andrea B. Pembe, Edmund Kayombo, Columba Mbekenga, Pia Axemo and Elisabeth Darj. Birth preparedness and complication readiness a qualitative study among community members in rural Tanzania Glob Health Action 2015, 8: 26922 http://dx.doi.org/10.3402/gha.v8.26922

13. Musa A, Amano A (2016) Determinants of Birth Preparedness and Complication Readiness Among Pregnant Woman Attending Antenatal Care at Dilchora Referral Hospital, Dire Dawa City, East Ethiopia. GynecolObstet (Sunnyvale) 6:356. doi:10.4172/2161-0932.1000356

14. Mukhopadhyay DK, Mukhopadhyay S, Bhattacharjee S, Nayak S, Biswas AK, Biswas AB. Status of birth preparedness and complication readiness in Uttar Dinajpur District, West Bengal. Indian J Public Health 2013;57:147-54

15. Markos Desalegn, Bogale Daniel. Birth preparedness and complication readiness among women of child bearing age group in Gobaworeda, Oromia region, Ethiopia.BMC Pregnancy and Childbirth201414:282 DOI: 10.1186/14712393-14-282

16. Kuganab-Lem Robert B, Razak Dogudugu $^{2}$, Ladi Kanton. Birth Preparedness and Complication Readiness: A Study of Postpartum Women in a Rural District of Ghana.s.l. Reproductive Health: 
2011 Nov 16;8:33. doi: 10.1186/17424755-8-33.

17. Graneheim UH, Lundman B. Qualitative content analysis in nursing research: concepts, procedures and measures to achieve trustworthiness. Nurs Educ Today. 2004;24:105-12.[PubMed]

18. Coverage Evaluation Survey: National Fact Sheet . s.1. : UNICEF, 2009. 